\title{
In conversation with H. Steven Greer
}

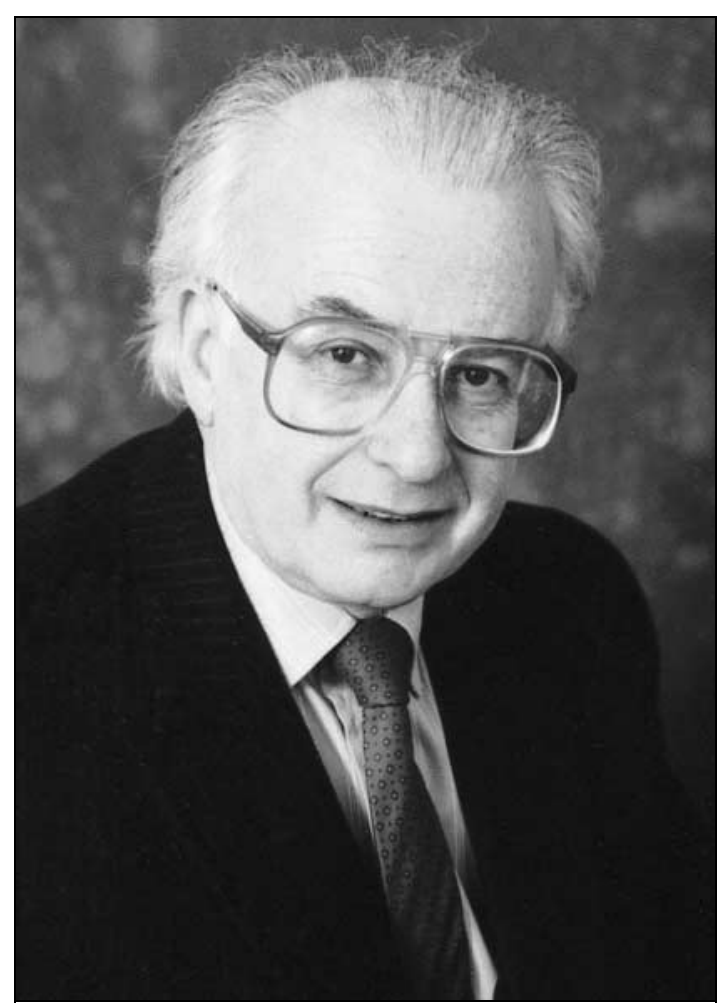

Dr H. Steven Greer read medicine at the University of Adelaide, South Australia, graduating in 1952. His subsequent medical training was at the Royal Perth Hospital, Western Australia. He came to London in 1957 and trained in psychiatry at the Maudsley Hospital from 1957-1960. After a year as a senior registrar at Cane Hill Hospital he returned to Perth, where he worked as a consultant psychiatrist for four years. Returning to London in 1964, he was appointed Lecturer (Reader in 1968) in Psychological Medicine at King's College Hospital Medical School, where he remained until 1986. His research at first centred on parasuicide, and from 1971 onwards on psychological aspects of cancer. Together with medical colleagues he founded the Faith Courtauld Unit for Human Studies in Cancer (funded by Faith Courtauld) and the British Psycho-Oncology Society. As a result of his research he was invited to join the Royal Marsden Hospital, where he set up the
Department of Psychological Medicine. He was awarded the Sutherland Memorial Award for pioneering work in psycho-oncology in 1996 in New York. Since 1996, he has worked part-time at St Raphael's Hospice in Cheam. He is co-author of several books and many papers and continues to write and lecture.

\section{Why did you choose to study medicine?}

I think it was mainly because my father was a doctor and I had a very close relationship with him and he stimulated my interest in medicine.

\section{And why did you choose psychiatry as a speciality?}

I became interested in psychiatry because I recognised that in both the teaching hospital where I worked in Australia, the Royal Perth Hospital, as well as subsequently in general practice, many of the symptoms which patients showed, medical and gynaecological patients, and others that I saw, were not related to any obvious organic disease and so I became more and more interested in psychiatry as a result of that.

So then you went to the Maudsley. What were your impressions of the Maudsley at that time?

I started at the Maudsley in April 1957. My first impression, I'm sorry to say, was a very bad one. On the first day I was there one of the registrars was asked to show me around and introduce me to people. He was very nice and he did this. He showed me the library and the wards and so on. At lunch time we repaired to the local pub, which was the Fox on the Hill, and over lunch I asked him what his general impression was of the Maudsley and whether he was enjoying his time there and he said, and I'll never forget this, "It's a very good place to work and to learn about psychiatry, but there is one major problem: there are too many bloody Jews". I must say I was absolutely appalled that the pernicious disease of antisemitism should be present, of all places, at the Maudsley and, of all people, in psychiatrists.

Subsequently, I spent three years there and I enjoyed my time very much. I was impressed by the obvious intellectual rigour of Aubrey Lewis and I still to 


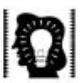

special articles this day, when I'm writing a paper, think of him saying over my shoulder, "When you write that sentence, what is your evidence?" I was impressed too with the teaching there. The person who taught me most about clinical psychiatry was John Wing, the subsequent Professor of Social Psychiatry. I had some colleagues who later became quite famous, we had a good year. One was the late Bob Cawley, whom everybody knew and who became a very close friend of mine. I regard him as probably the wisest and most intelligent person I ever met. Also in our year were other luminaries, such as Colin Murray Parkes, of bereavement fame, Mike, now Sir Michael Rutter, and Norman Kreitman, who later headed a Medical Research Council Social Psychiatry Unit in Edinburgh. While I was at the Maudsley, I assisted Michael Shepherd with his major paper, 'Morbid jealousy' and completed my MD thesis on the natural history of neurotic illness. I enjoyed my time there and I was sorry to leave.

Later you got a job at King's College Hospital and you must have been one of the first liaison psychiatrists. What were your impressions of King's and how did you become interested in patients with cancer?

A few years elapsed. I went back to Australia, spent a few years there and then came back and got a job at King's at the end of 1964. It was a challenge. I had a job which was half-time as a lecturer in the Department of Psychiatry and half-time attached to the Professorial Unit of Medicine. I enjoyed this very much because it enabled me to learn more about medicine and also to practise and learn about liaison psychiatry. I was very lucky in that one of the physicians, with whom I later did quite a lot of research, Keith Pettingale, was very interested in psychological medicine. We used to run tutorials for medical students in which we looked not just at medical conditions, but at the psychiatric and social sequelae of various medical illnesses, when we interviewed patients in front of the students. Later I obtained private funding to look at psychological aspects of cancer. I was very fortunate in that a radiotherapist there, Dr Diana Brinkley, started referring me women with breast cancer and so I became interested in this topic. We got some money to set up a research unit from Faith Courtauld and Keith Pettingale, Dudley Tee, an immunologist and pathologist there, and I set up the Courtauld Unit for Human Studies in Cancer and that began what has remained a lifelong interest for me.

Could you tell me how you then came to set up the Department of Psychological Medicine at the Royal Marsden Hospital?

Because of the work we did on the Courtauld Unit, which was published and became known among some oncologists, in 1986 Professor McElwain from the Royal Marsden invited me to join him there, and in order to obtain the money for a post there I wrote a research application to the Cancer Research Campaign for a fiveyear programme grant and that enabled me, with his help, to set up a unit at the Royal Marsden. I was well received. There was considerable interest in what I was doing. The only problem was, as I've found in every other job I've had, was not with doctors, not with patients, not with colleagues of any kind, but with administrators, who, as everywhere else, are penny-pinching and obstructive.

\section{Could you give me an example of this?}

Yes, I realise this is a rather provocative statement, but I really believe it to be true. Just to give you one example: after I'd been there a couple of years I obtained money for an additional research assistant from the Cancer Research Campaign, who were very generous and reasonable. Shortly after the assistant started work I had a phone-call from a senior administrator asking me why I needed a desk and chair for her and that this wasn't an expense which he could justify. That kind of obstruction is precisely what I mean and what still makes life difficult for doctors in the National Health Service.

I was wondering whether you found it at all difficult being the only consultant psychiatrist in a large, medically-oriented hospital?

Well, I didn't regard this as a problem, I think because my experiences of medicine at King's, on the Professorial Unit, helped me to relate well to physicians, to talk their language and be accepted by them as relatively normal for a psychiatrist. Some of the senior registrars from the Maudsley rotation, who came to work in our unit, asked me the same question. They enjoyed their work at the Marsden, but when I tried to get them to take up psycho-oncology as a career, they said that although they found it interesting, they were worried about being the only psychiatrist in a medical milieu. But I must say I did not find that. I was very happy at the Royal Marsden. I didn't really find any serious problems with my colleagues at all.

What do you regard as your most significant contributions to psycho-oncology?

I think my colleagues and I have made several contributions which I regard as interesting. First, we really founded psycho-oncology as a sub-speciality in Britain. That began while I was still at King's. As far as research is concerned, the three contributions that I found interesting, and I hope other people found interesting, were in a controlled study, where we studied women with suspicious breast lumps before surgery and before they, or we, knew the diagnosis, we showed that there were personality differences between women who later turned out to have breast cancer and women who later turned out to have benign breast disease and this became known as the Type C Personality. There has been a lot of argument about this, but nevertheless I think it's an interesting and stimulating finding. Second, we showed that certain mental or psychological attitudes to cancer could have an effect on duration of survival again in women with breast cancer. And we carried out a 15-year follow-up study which confirmed this. Third, and 
to me the most important contribution perhaps, is that Stirling Moorey and I developed a form of psychotherapy, based on cognitive-behavioural principles, which we called 'adjuvant psychological therapy', and which, as we showed in several randomised controlled studies, improved the life of cancer patients significantly.

You are the person, who, more than anyone else, has put 'fighting spirit' on the map. A recent paper in the Lancet by Maggie Watson and others - you are one of the co-authors - failed to confirm the link which you had found earlier between fighting spirit and improved length of survival. How do you explain this discrepancy?

It's difficult to be absolutely certain, but in my view, the problem rests with the measurement of fighting spirit.

The original study (Greer, Pettingale, Morris) used clinical ratings to measure coping styles. The Watson study used the MAC (Mental Adjustment to Cancer) scale. In a subsequent study, the MAC scale measurement of fighting spirit was shown to be faulty: of the 16 items comprising fighting spirit on the MAC scale, only four were retained in the new Mini-MAC scale. This may account for the lack of correlation between fighting spirit (as measured by the MAC scale) and longer duration of survival. What is interesting is that the polar opposite of fighting spirit, namely hopelessness and helplessness, which we also measured, was still, in the Lancet study, significantly associated with reduced duration of survival. So it makes sense to suppose that the opposite, which is fighting spirit, is associated with better outcome, even if it did not show up in that study.

Recently you have become increasingly interested in psychoneuroimmunology. What views do you have about this relatively new field, and in general about the mind-body problem?

Yes, well I'm glad you asked me to try and solve a problem that no one else so far has been able to solve! All I can say about the mind-body problem, and it's certainly not very original, is that we are still suffering from the baneful influence of René Descartes, who in 1641 announced in his Meditations this rigid separation between mind and body, or in his words soul and body. I'm a monist, pure and simple, and I think most people in this field are. But the finer points of this argument elude me, as they have eluded people much brighter than I can ever hope to be.

Now, psychoneuroimmunology is a very interesting field and I have tried, unsuccessfully so far, to persuade many, or indeed any, of my psychiatric colleagues to become involved in this. There is no question in my mind that this is one important way of studying mind-body relationships and I will continue with my efforts to try and persuade colleagues, including yourself, to take an interest in this field. What has been discovered - which is most fascinating - is that there is definite communication between the central nervous system and the immune system, communication in both directions. There is compelling evidence of this. Perhaps, among all the evidence, if I could just mention one point which has impressed me most is that it has been shown that mobile cells in the immune system have on them receptors for neuropeptides and this a very important method of communication between the central nervous system and the immune system. Some very interesting research is being done. But the only sustained research in this field that I am aware of in Britain has been carried out by Lesley Walker and his colleagues in Aberdeen. He has now moved to Hull and become a professor there. He is a psychologist who has contributed greatly to this field and has shown that certain psychological interventions actually produce measurable changes in immune activity. It is a great pity that psychiatrists have shown little or no interest in this field so far, but I hope this situation will change.

We've talked a bit about some of your achievements in psycho-oncology, but what about your failures?

Yes, well, I have had many failures, many more failures than achievements. Among my main failures is my failure to interest psychiatrists, particularly junior psychiatrists, with whom I have come into contact, either in psychooncology or in psychoneuroimmunology. Among many other failures, I suppose the one that stands out and which I would like to mention is that I've always objected strongly, on ethical as well as on scientific grounds, to stress experiments on animals. I've been involved in arguments with people and on one occasion years ago, in a deputation, I saw a junior minister in the Home Office to try and persuade him to issue more stringent laws about this. I've completely failed to persuade even a single psychologist or psychiatrist to stop carrying out these experiments, which I think are unethical and redundant. They are just unnecessary because of the enormous amount of stress which human beings suffer from and which should be studied, and there seems to be an attitude which says that animals can be treated in whatever way we like, provided we can obtain information which will enable us to get publications which we need for our future careers.

You've worked in the National Health Service for a number of years and seen many changes. What changes do you think are for the better and what changes are for the worse?

I find it difficult to think of any changes for the better since I first began in the NHS many years ago. If you want to know about changes for the worse, I would say that these began with, and are directly attributable to, the development of trusts and the idea of the internal market, which was introduced by Virginia Bottomley and her minions in the previous government. I think these have been very detrimental influences on the NHS and have led to many of the problems that we presently face. 
18

special articles
You have now retired from full-time work in the NHS, but you are still working part-time at St Raphael's Hospice in Cheam. How do you find the work there?

This is hard for people who have never worked in a hospice to believe, but it is the best job I've ever had, certainly in terms of the atmosphere there. There is no empire building, there is no back-biting, people address each other by their first names, we all get on extremely well, there are no obvious disputes about territorial boundaries between nurses and doctors and social workers and so on. It's an extremely pleasant place to work and I'm enjoying it very much. I'm very fortunate in that I'm working with a medical director whom I knew at the Royal Marsden, Joe Ford, who joined me at St

Raphael's and with whom I have a very good relationship. $\mathrm{He}$ is a superb palliative care physician and oncologist. I'm very happy there in every respect.

\section{What are your main interests outside psychiatry?}

I have had an opportunity, because of partial retirement, to develop other interests. One of these which is, and always has been, very important to me, is the question of animal welfare and I'm involved in various organisations which try to espouse the cause of animal welfare and oppose things like hunting and exporting of live animals and so on. I've also become very interested in modern history and have been reading up a great deal on the history of Europe since 1789. I've also become interested in ethology and evolution and the various theories to do with that and I've come across a book which I would like to recommend to psychiatrists, which I think is one of the most stimulating books I've ever read. It's called Shadows of Forgotton Ancestors: a Search for Who We Are. It's a book about evolution, beautifully written, by Carl Sagan and Ann Druyan. 